\title{
FIBRAS DE CARBONO NA CONSTRUÇÃO CIVIL
}

\section{Nicolas Montanari ${ }^{1}$ \\ Erika Peterson Gonçalves ${ }^{2}$}

Resumo: Os materiais compósitos se dão pela utilização de dois, ou mais, materiais trabalhando de forma conjunta com o propósito de alcançar determinada propriedade a qual não seria possível com os mesmos isolados. A fibra de carbono com resina epóxi utilizada em reforços estruturais é um desses materiais, a grande resistência mecânica à tração e elevado módulo de elasticidade tornam a fibra de carbono adequada do ponto de vista estrutural, e com a resina epóxi atuando de modo a transferir as tensões da estrutura para serem resistidas pela fibra a caracteriza como tal. Este processo de reforço já vem se mostrando uma alternativa a métodos tradicionais, é mais rápido, simples e limpo que outros, clientes vem optando por este processo mesmo que apresente custo final mais elevado, pois quando consideradas as vantagens nele embutidas torna-se viável. Muito já se desenvolveu com a fibra de carbono no ramo da construção civil, porém ainda pode ser feito mais, descobrindo e aperfeiçoando novas técnicas construtivas compostas de materiais com fibra de carbono.

Palavras-chave: Compósitos estruturais; Fibra de carbono; Reforço com fibra de carbono.

\footnotetext{
${ }^{1}$ Engenharia Civil/Universidade do Vale do Paraíba - UNIVAP, Brasil. E-mail: nicolas.montanari@yahoo.com.

2 Engenharia Civil/Universidade do Vale do Paraíba - UNIVAP, Brasil. E-mail: erika@univap.br.
} 